\title{
EI Maestro Heriberto Arcila Herrera: EI Médico, el Investigador y el Humanista
}

\author{
Renán A. Góngora-Biachi \\ Centro Médico de las Américas
}

Escribir la semblanza biográfica del Dr. Heriberto Arcila Herrera representa, para un servidor, una gran distinción y un alto honor; y lo es porque, por vez primera, en un documento, voy a referirme a mi Maestro.

Conocí al Dr. Heriberto Arcila cuando cursaba el quinto año de la carrera y él regresaba de la ciudad de México vía Mexicali, siendo ya un nefrólogo y académico distinguido, donde hizo una breve estancia médica por invitación de su hermano Enrique. El sitio del encuentro fue el Instituto Neuropsiquiátrico, que dirigía con entusiasmo su fundador, el Dr. Raúl Cárdenas Torre, cuyo liderazgo se traducía en un ambiente festivo aunque, a la vez, disciplinado de trabajo. El Maestro Cárdenas, fue un médico que distinguió y apreció al Dr. Arcila desde la época estudiantil; también, fue el promotor principal de su formación de postgrado. De hecho, inicialmente el Dr. Arcila había sido motivado para estudiar neurocirugía en Cleveland, con el famoso neurocirujano Dr. Garner. Curso que tuvo que posponerse, por un compromiso con una beca que el Dr. Cárdenas había conseguido de los Laboratorios Farbiosa para algún médico yucateco y que, como bateador emergente, le tocó al Dr. Arcila al no aceptarla el candidato original. Así pues, no era fortuito que al retornar al terruño tuviera un sitio en el centro hospitalario que dirigía tan distinguido maestro de la medicina yucateca.

Recuerdo que la primera entrevista con el Dr. Arcila se centró en cuanto a mi interés por las ciencias básicas y mi disposición a la enseñanza de éstas. Para esas épocas, hablo de febrero de 1975, el Maestro Arcila ya tenía el nombramiento de Jefe del Departamento de Fisiología de la Facultad de Medicina de la Universidad de Yucatán y estaba en proceso de integración de su equipo, incluyendo ayudantes del departamento, categoría que me fue ofrecida, por lo que me integré, parcialmente, a ese equipo en septiembre de ese año, cuando ingresé al internado, utilizando los tiempos libres que el Hospital O'Horán nos concedía.

El 12 de octubre de 1975, el Dr. Alberto Rosado G. Cantón, entonces Rector de la Universidad de Yucatán, fundó el Centro de Investigaciones Regionales "Dr. Hideyo Noguchi”, integrado por cuatro Departamentos: Biología de la Reproducción, a cargo de la Dra. Thelma Canto de Cetina, Patología Tropical que tenía como responsable al Maestro Jorge Zavala Velásquez, el de Hematología, a cargo del Dr. Rosado G. Cantón y el de Fisiología que dirigía el Dr. Heriberto Arcila Herrera. Este hecho permitió al maestro Arcila abrir la opción de servicio social en ese sitio siendo así como pudieron integrarse los primeros alumnos tutelares del maestro, entre ellos, el Dr. Carlos Ruz Díaz, el Dr. José Pasos Peniche, el Dr. Jaime Herrera Hoyos, el Dr. Herbert Novelo Rosado+, el Dr. Efraín Ceh Castillo, el Dr. Pedro Suárez Alpuche, el Dr. Carlos Martínez Bolio y, por

Autor para correspondencia: Dr. Renán Góngora Biachi, Centro Médico de las Américas, Calle 54 No. 365 x Av. Pérez Ponce y 33-A, Mérida, Yucatán, México. E-mail: gbiachi@correo.uady.mx

Recibido: el 26 de marzo de 2015 Aceptado para publicación: el 7 de abril de 2015

Este artículo está disponible en http://www. revbiomed.uady.mx/pdf/rb152618.pdf

Vol. 26, No. 1, enero-abril de 2015 


\section{Góngora-Biachi}

supuesto, un servidor, entre otros compañeros que actualmente ocupan posiciones académicas trascendentes, locales e internacionales; al concluir sus doctorados en ciencias fisiológicas, farmacológicas o neurociencias. A este grupo también se integraron pasantes de la Facultad de Química, entre las que destacan las QFB Dorita Lara Perera, Alicia Córdova y Azeneth Pinto. Así, el Maestro Arcila había creado ya su propia "escuela", de la que sus alumnos nos sentíamos y sentimos muy orgullosos de pertenecer a ella.

El Maestro Heriberto Arcila, es egresado de la Facultad de Medicina de la Universidad de Yucatán, realizó la especialidad de Nefrología en la primera escuela de Nefrología de México, en el Instituto Nacional de Cardiología "Dr. Ignacio Chávez"; e integró la primera generación de nefrólogos del país, bajo la tutela del Maestro Herman Villarreal, pionero de esta especialidad en el México y Latinoamérica. La disciplina del Maestro Villarreal, la convivencia académica con maestros de la talla del Dr. Ignacio Chávez, del Maestro Demetrio Sodi Pallares, del Dr. Carlos Méndez (un cardio-fisiólogo español refugiado de la guerra civil española), entre otras personalidades del mundo científico, forjaron, sin duda, en el Dr. Arcila ese espíritu académico enfocado a la investigación; Durante su permanencia en el Instituto Nacional de Cardiología, que fue de febrero de 1962 a julio de 1973, el Dr. Arcila realizó una estancia como investigador en Fisiología en la Universidad de Cornell en 1966, y otra de noviembre de 1970 a abril de 1971 en la Clínica Médica del Hospital Broussais de París. También fue profesor de la Clínica Cardiovascular de la Facultad de Medicina de la Universidad Autónoma de México de 1968 a 1973. Desde 1976, es académico titular de la Academia Nacional de Medicina; además, es asociado de la Sociedad Mexicana de Cardiología, de la Sociedad Mexicana de Nefrología y fue presidente fundador y socio actual de la Academia Yucateca de Medicina y Cirugía.
Como ya he comentado, de regreso al terruño, el Dr. Arcila se integró como docente al la Facultad de Medicina de la Universidad de Yucatán y como Profesor Investigador fundador del Centro de Investigaciones Regionales "Dr. Hideyo Noguchi", de la misma universidad, puestos que desempeñó hasta su jubilación de esta institución. En especial, su participación como maestro de Fisiología logró un respeto hacia su persona, respeto que hoy se transforma en reconocimiento de parte de sus ex alumnos, que acumulan casi treinta generaciones. Por diez años fue médico nefrólogo del Hospital Escuela O’Horán y recuerdo su amistad y admiración para otro gran médico, el Dr. Ricardo López Hernández+, maestro de muchos médicos egresados de la Facultad de Medicina de la Universidad de Yucatán (hoy Autónoma de Yucatán).

Debo destacar que, como investigador siempre contó con el apoyo de la Q.F.B. María Francisca González Franco, Paquita, su distinguida esposa; con quien trabajó y sigue trabajando desde 1963, época en que la conoció en el Instituto Nacional de Cardiología. Como las buenas novelas de amor, fueron novios y casaron en 1967, en la tierra natal de Paquita, Guadalajara. Desde entonces la frase "detrás de un gran Arcila hay una gran Paquita", es ya famosa.

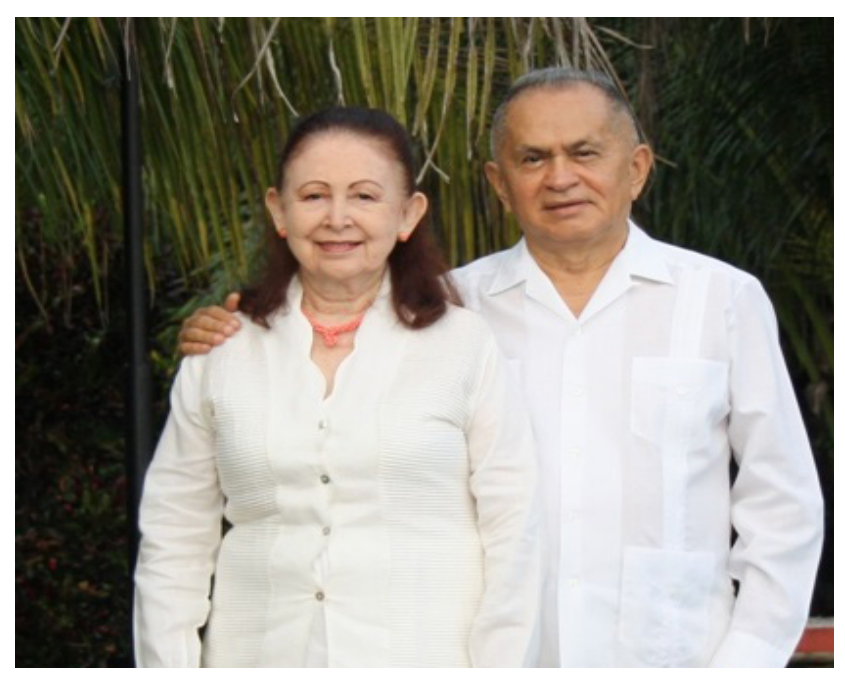




\section{Semblanza de Heriberto Arcila-Herrera}

El Dr. Arcila es autor de 39 publicaciones científicas y muchas de ella de gran impacto por la trascendencia de los conceptos emitidos en ellas, los cuales han sido validados en nuestra época. Así, y a manera de ejemplo, puedo referirme a su trabajo publicado en el American Journal of Physiology en 1962, en donde describe el papel de la L-arginina como fuente de la urea y su nulo papel -como se concebía en esa épocaen la protección de la intoxicación amoniacal. O sus trabajos pioneros de la angiotensina en el transporte renal de sodio y la génesis de la hipertensión, publicados en los Archivos del Instituto Nacional de Cardiología y en el American Journal of Cardiology, en 1964 y 1967, respectivamente. Sendos trabajos publicados en el American Journal of Phisiology y en Nephron, en 1968, describen los mecanismos farmacológicos en el ámbito enzimático del mecanismo de acción de los diuréticos, vigentes hoy en 2015, cuarenta y siete años después. Los trastornos metabólicos de la insuficiencia renal fueron descritos por el Dr. Arcila en la revista British Medical Journal en 1972. También, como un estudioso de la hipertensión arterial, el Dr. Arcila ha contribuido con varias publicaciones en este tema. La fisiopatogenia de la pre-eclampsia y de la eclampsia fue un tema del que tuve el honor de participar con él en tres publicaciones y que, además, fue tema de mi tesis profesional, dirigida por el Profesor Arcila. Su mente siempre ágil para identificar problemas clínicos le permitió describir y publicar en 1998, en la Revista de Investigación Clínica, diez casos de ciguatera, intoxicación por toxinas que se produce al ingerir carne de barracuda.

Y es que, como médico, el maestro tiene el don de la paciencia que permite escuchar, entender y consolar a sus pacientes. Como él mismo describe en un Editorial de Revista Médica del Centro Médico de las Américas, de la que es Editor: "El médico debe ser amo de sus silencios y esclavo de sus palabras. Amo de sus silencios en el deber de la secrecía, de la intimidad doliente de su paciente. Ese diagnóstico que no es sólo patología, sino historia íntima de un humano que sufre. Historia de vidas reveladas en el confesionario del consultorio del médico-sacerdote. Secretos de honras destruidas, de esperanzas fallidas, pesares, emociones, que tú, médico, debes aceptar en empatía con tu paciente...”.

Otra virtud del Médico Heriberto Arcila, es su capacidad de realizar silogismos clínicos que le permiten crear marcos fisiopatogénicos, que se traducen a su vez, en posibilidades diagnósticas certeras. Recuerdo aún las interconsultas en el Hospital O'Horán que se convertían en una cátedra de clínica médica por parte del Maestro. El Dr. Arcila es un médico querido, respetado y buscado por sus pacientes, a pesar que él mismo anunció su retiro y cerró el famoso consultorio de la calle 59-A, en donde en forma discreta, en ausencia de una placa que anunciara el consultorio y de una secretaria, entre ventanas de la herrería, había un número telefónico a donde había que comunicarse para obtener una consulta. Una manera diferente y humilde de ejercer la medicina privada.

$\mathrm{Su}$ entusiasmo por los avances médicos en el terruño, lo motivaron a que junto con el Dr. Luis Mario Baeza Mezquita, el Dr. Joaquín Ortiz Ordaz, el Dr. Luis Fernando Flota Cervera, el C.P. Fernando Ojeda Llanes y un servidor, iniciáramos, hace ya poco más de 30 años, el proyecto del Centro Médico de las Américas, centro hospitalario líder del sureste de México, del cual festejamos ya el trigésimo aniversario de inauguración.

Como maestro y compañero de trabajo, disfruté 26 años la compañía del Dr. Arcila. En ese lapso, pude descubrir al humanista y culto médico. De él aprendí que ser firme en nuestras actitudes y perseverante en nuestros ideales, es un camino seguro hacia el éxito. Que el éxito en la vida no se mide por lo que has logrado, sino por los obstáculos que has tenido que enfrentar en el camino. Que no hay que esperar a las 


\section{Góngora-Biachi}

oportunidades, hay que ir a buscarlas. Que hay que ver cada problema como la oportunidad de encontrar una solución. Que hay que ver en cada desierto la oportunidad de encontrar un oasis. Con la convivencia del maestro descubrimos que nuestro único rival no son más que nuestras propias debilidades.

Su lenguaje metafórico para ejemplificar las cosas simples o complicadas, su convicción por la justicia y la honradez, el valor que le otorga al entorno familiar (manifestado por el amor recíproco de su esposa Paquita, de sus hijos Pili, Francis, Heriberto, así como de sus yernos, de su nieto y de su hermano Enrique) y su concepto en la verdadera amistad, hacen del maestro Heriberto Arcila, mi Maestro, un ser humano admirable y un paradigma a seguir. 